\title{
Reasons and multilevel factors associated with unscheduled contraceptive use discontinuation in Ethiopia: evidence from Ethiopian demographic and health survey 2016
}

Kibrom Taame Weldemariam ${ }^{1 *}$, Kebede Embaye Gezae ${ }^{2}$ and Haftom Temesgen Abebe ${ }^{2}$

\begin{abstract}
Background: Contraceptive discontinuations for reasons other than the desire for pregnancy are a public health concern because of their negative effect on reproductive health outcomes. In Ethiopia, the contraceptive discontinuation rate is increasing; however the factors associated are poorly understood. So this study was aimed at assessing reasons and multilevel factors for unscheduled contraceptive use discontinuation.

Methods: This is a cross-sectional study of Ethiopian women who participated in the Ethiopian demographic health survey from January 18, 2016, to June 27, 2016. Ever using any contraceptive with in the calendar of the survey were an inclusion criteria for which 3835 women were found eligible. The data were analyzed using multilevel binary logistic regression in STATA version 14 . Variables with $p$-value less than 0.05 were considered as statistically significant, and reported using adjusted odds ratio and 95\% confidence interval. Median odds ratio and interval odds ratio, to quantify the magnitude of the general and specific contextual effect respectively, were used. Receiver operating characteristics curve and akaike's information criterion were used for model comparison.

Result: The prevalence of unscheduled contraceptive use discontinuation was $46.18 \%$ for the principal reason of method related problems (Side effects-45.3\%, needing better method-33.6\%, and inconvenience-21.1\%,). Women heading a household ( $\mathrm{AOR}=1.281,95 \% \mathrm{Cl} 1.079-1.520)$, women who had no work (AOR $=0.812,95 \% \mathrm{Cl} 0.673,0.979)$ compared to professionals, living in poorest house hold income $(A O R=0.753,95 \% \mathrm{Cl} 0.567,0.997)$ compared to middle, residing in community with low contraceptive utilization rate $(A O R=1.945,95 \% \mathrm{Cl} 1.618,2.339)$, residing in poor community ( $A O R=0.763,95 \% \mathrm{Cl} 0.596-0.997)$, and having more children, and region were found to be significant predictors of unscheduled contraceptive use discontinuation.

Conclusion: Method related problems were found to contribute for more than half of the contraceptive use discontinuation. Both individual and community level factors were found to significantly influence the Unscheduled contraceptive use discontinuation. The outcome was common in groups who could have more social interactions and knowledge on which myths and rumors are common. So strengthening the efforts to reduce contraceptive use discontinuation and quality of contraceptive service provision could be important.
\end{abstract}

Keywords: Contraceptive, Discontinuation, Ethiopia, Factors, Health, Multilevel, Survey

\footnotetext{
* Correspondence: kibrom.taame@yahoo.com

1 Department of Biostatistics, School of Public Health, College of Health

Sciences, Aksum University, P.O.Box: 298, Axum, Ethiopia

Full list of author information is available at the end of the article
}

(c) The Author(s). 2019 Open Access This article is distributed under the terms of the Creative Commons Attribution 4.0 International License (http://creativecommons.org/licenses/by/4.0/), which permits unrestricted use, distribution, and reproduction in any medium, provided you give appropriate credit to the original author(s) and the source, provide a link to the Creative Commons license, and indicate if changes were made. The Creative Commons Public Domain Dedication waiver (http://creativecommons.org/publicdomain/zero/1.0/) applies to the data made available in this article, unless otherwise stated. 


\section{Introduction}

Discontinuation of contraception method is an abandonment of contraceptive method utilization among women who ever use contraception for any reason [1]. Women with unmet need are defined as those who want to stop or delay childbearing but are not using modern contraceptive methods [2]. Unscheduled contraceptive use discontinuation is an abandonment of contraceptive utilization despite the desire to avoid pregnancy.

Although there is an increase in contraceptive prevalence rate (CPR), worldwide $38 \%$ women using family planning discontinue their contraceptive method without switching to another method, despite their desire to avoid pregnancy [3]. 64\% women discontinued their contraceptive use by the 36th month [4]. Greater than a half of women who start using a modern contraceptive method stop using it before two years of continual utilization [1].

Discontinuation for reasons other than wanting to become pregnant has a big contribution to unplanned pregnancies, unwanted births, unwanted fertility and termination of pregnancies that may be done through unsafe abortion $[2,5]$.

Tackling discontinuation has been highlighted as a key global health issue [6]. However; a main obstacle to reduce unwanted fertility is the discontinuation of modern contraception [1]. One-third of unintended pregnancies are due to method failure or discontinuation [7, 8]. In countries with moderate to high contraceptive prevalence, the majority of unintended pregnancies are the result of contraceptive discontinuation or failure [9].

Investing in family planning accelerates achievement across the five Sustainable Development Goal (SDG) themes which are the five P's (People, Planet, Prosperity, Peace, and Partnership) [2]. So if FP2020 is to reach an additional 120 million women with an unmet need for family planning by 2020, family planning programs need to escape their selves from becoming a "leaking bucket" [10] in order to effectively addressed contraceptive discontinuation.

Therefore; promotion of continuation rates and re adoption among past users is better than promotion of new acceptance rates, because unwanted and mistimed pregnancies would increasingly result from discontinuation of methods rather than not ever using contraceptive at all [11]. Contraceptive discontinuation for reasons other than the desire for pregnancy is a public health concern due to its negative reproductive health outcomes consequences [12].

In sub-Saharan Africa countries, even though contraceptive use is rising, contraceptive discontinuation rates are also highly increasing [13]. According to the World Bank collection of development indicators, compiled from officially recognized sources, contraceptive prevalence among women ages 15-49 in Ethiopia was reported at $35.9 \%$ in 2016 . So this indicates a moderate contraceptive prevalence rate during the year of 2016.

In the study done in 2015, 25\% of reproductive age women had discontinued their contraceptive utilization [14], whereas the study done in 2017 stated that $27.4 \%$ of women discontinued their contraceptive utilization within 24 months [15]. In EDHS 2016, the overall discontinuation rate, including for the reason of wanting to become pregnant, was $35 \%$. So, discontinuation rate of modern contraceptive, in Ethiopia, is increasing. Despite a high level of knowledge majority of male and female showed negative attitude toward the contraceptive practicing [16].

In Ethiopia, almost all studies done on contraceptive use discontinuation were based on a single level analysis, however; the multilevel factors that could affect the contraceptive use discontinuation, using multilevel analysis, are not well addressed. For data with a hierarchical nature, unlike single level analysis, using multilevel models that allow one to account for the clustering of subjects within clusters of higher-level units when estimating the effect of subject and cluster characteristics on subject outcomes, would give us appropriate parameter estimation [17]. Limited evidences are available regarding multilevel predictors of contraceptive use discontinuation in Ethiopia at nationally representative sample.

Moreover; the studies that have been done on factors associated with contraceptive discontinuation was done on all women including those discontinued for the reason of wanting to get pregnant and on all episodes of discontinuation; so this could lead to complex results. For example, one could conclude that the odds of discontinuation is higher in the age group of 25-34 than of 15-24, but this might be due to higher need of to be pregnant in the 25-34 age group. Using data from overlapping contraceptive calendars, more than one-third of women were discordant in their reports for the reference month in the two surveys; and women using with more complex reproductive histories, including more births and more episodes of contraceptive use, were least likely to report reliably [18]. Therefore; this study uses the last method discontinued in the last five years prior to the survey to increase reliability by reducing recall bias. There were also additional factors like reasons for contraceptive discontinuation collected in EDHS-2016.

So this study has taken a step further from the routine EDHS report by further analysis of DHS data using advanced analysis model to assess reasons and multilevel factors of unscheduled contraceptive use discontinuation using a multilevel logistic regression model and provides context specific information to program planners and policy makers.

For conceptual framework (refer Fig. 1). 


\section{Community level factors}

1. Regions

2. Place of residence

3. Community contraceptive experience

4. Average wealth index of the community

5. Community education

6. Community media exposure

\section{Individual level factors}

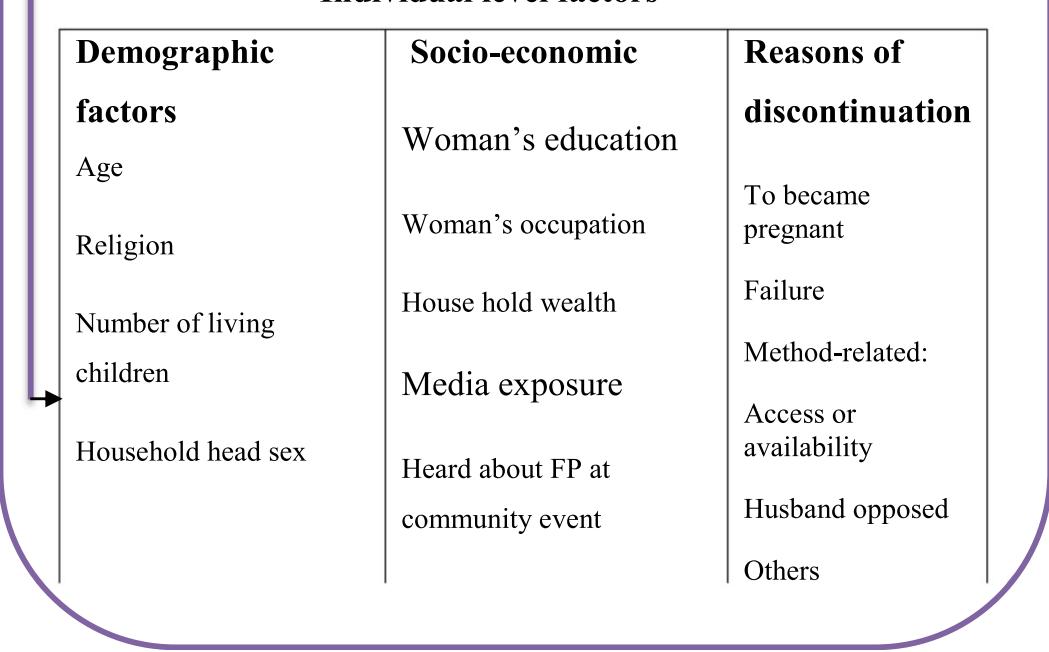

Fig. 1 Conceptual frame work of unscheduled contraceptive use discontinuation that conceptualizes the relationship of individual and community level predictors to the outcome variable in Ethiopia, January 2018. Source: adapted from different literatures

\section{Methods and materials}

\section{Study area}

The study was conduct in Ethiopia in 2018 from EDHS 2016. According to Ethiopia Demographics Profile 2018, Ethiopia is the second-most populous nation on the African continent with 105,350,020 estimated populations and with $79.6 \%$ of its population living in rural areas. Administratively, Ethiopia is divided into nine geographical regions and two administrative cities. Ethiopia has been doing more efforts to increase family planning utilization and continuation through increasing the number of skilled providers delivering high-quality contraceptive services and to ensure access for all populations although there is no discontinuation specific effort [19].

\section{Study design}

A cross sectional study design was used to collect data from the EDHS 2016 data set for the current analysis.

\section{Population}

\section{Source population}

Reproductive age women who ever used contraceptive in the 5-years prior to the EDHS 2016.

\section{Study population}

Reproductive age women in the selected clusters who ever used contraceptive in the 5- years prior to EDHS 2016.

\section{Eligibility criteria Inclusion criteria}

All reproductive age women who ever used contraceptive in the 5-years prior to EDHS 2016.

\section{Exclusion criteria}

Women of reproductive age who discontinued contraceptive use for the reason of wanted to become pregnant. 
Sample size determination, and sampling procedure

EDHS 2016 used a multistage stratified cluster sampling method. The sampling frame used was adopted from the Ethiopia Population and Housing Census of 2007 that had complete list of 84,915 enumeration areas. 2016 EDHS sample was selected in two stages. Each region was stratified into urban and rural areas, yielding 21 sampling strata. Samples of enumeration areas were selected independently in each stratum in two stages. At second stage 28 households per cluster were selected. All women of 15-49 ages, in the selected households, were interviewed. A total of 15,683 women were successfully interviewed, yielding a response rate of $95 \%$ [20]. Schematic representation of sampling procedure (refer to Fig. 2).

\section{Study variable \\ Dependent variable}

The dependent variable is unscheduled contraceptive use discontinuation in the 5 years prior to the survey of 2016. This dependent variable was coded to have a binary response to the question "last method discontinued in the last 5 years" if discontinued "yes $=1$ " and "otherwise $=0$ ". This outcome variable was then modeled to historical predictor variables that were selected based on existing evidences.

\section{Independent variables}

Individual level variables Respondent's age group, respondent's occupation, respondent's education, Religion, Number of living children, heard about family planning at community -event/conversation, Household head sex, House hold wealth, and media exposure on family planning messaging.

Community level variables In addition to region, and place of residence, the aggregated values that are assumed to affect group level variation which are: Community contraceptive, average wealth index of the community, community education, and community media exposure on family-planning messaging were included.

The aggregated community level predictor variables were constructed by aggregating individual level values at cluster level, and binary categorization of the aggregated variables were done based on the distribution of the proportion values calculated for each cluster (community). Mean for normally distributed or median for not normally distributed community level aggregated predictor variables were used as cut off point for categorization. Histogram was used to check the distribution whether it is normal or not.

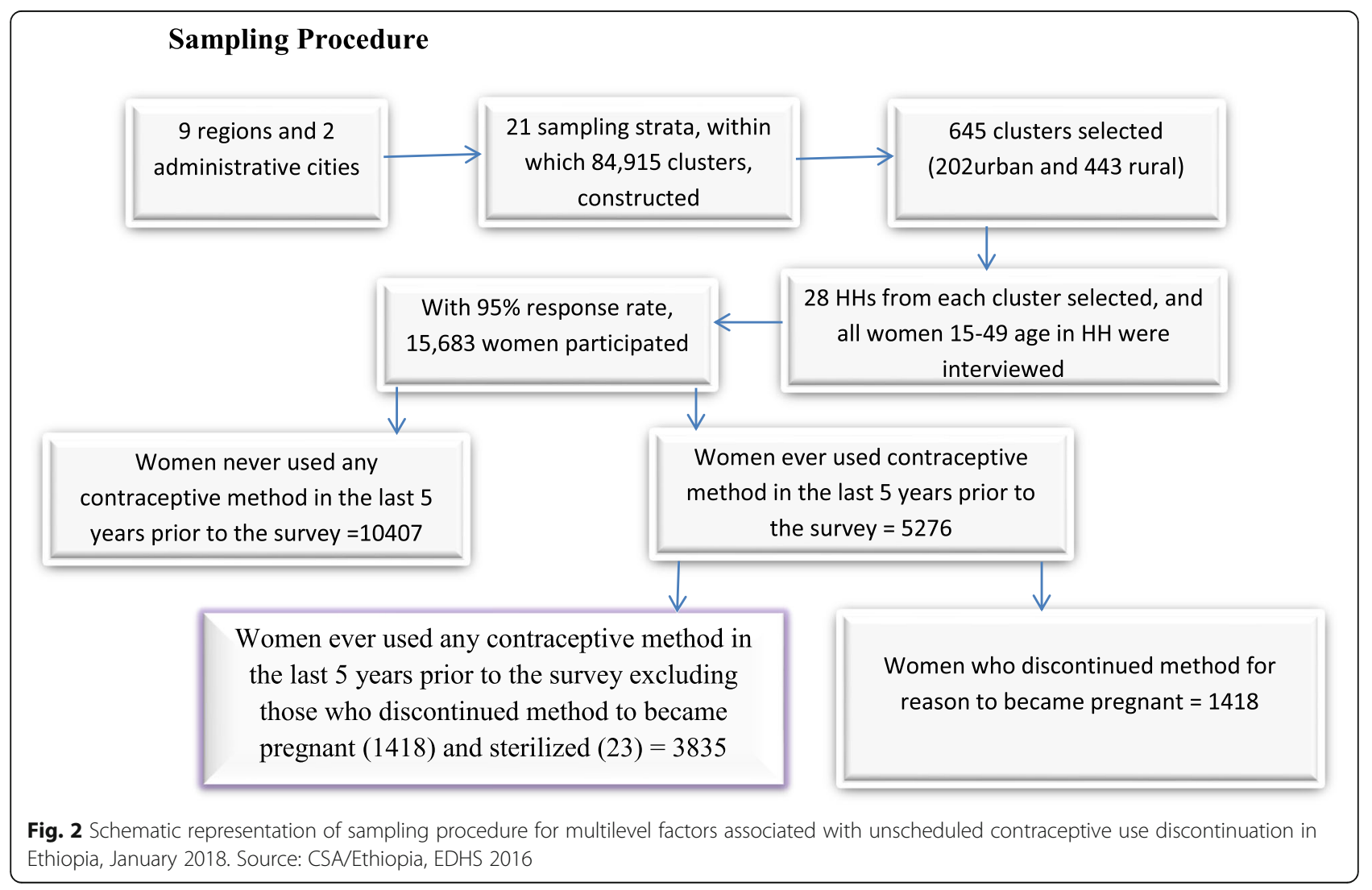


Community media exposure was categorized as exposed if the proportion of women in the community exposed to media was $>=26.087 \%$ and categorized as not exposed if the proportion was $0-26.087 \%$. Community education was classified as literate if the proportion women in a community attending high-school and above was $>=12.5 \%$ and as illiterate if the proportion was $0-12.5 \%$. Community wealth was categorized as rich if the proportion of women with richer and richest wealth quintile in one community was $>=43.478 \%$ and as poor if the proportion was $0-43.478 \%$. Community contraceptive rate was classified as high if the proportion of women utilizing contraceptive in a community was $>=20.833 \%$ and as low if the proportion was $0-20.833 \%$.

\section{Operational definition}

Unscheduled discontinuation: Unscheduled discontinuation of contraception method is an abandonment of contraceptive method utilization without switching to another method, despite their desire to avoid pregnancy.

From the reasons listed as a cause of discontinuation in EDHS-2016: discontinuation was classified in to two: Scheduled discontinuation: women who discontinued due to the need to become pregnant and Unscheduled discontinuation: women who discontinued for the reason other than desire to become pregnant. This unscheduled discontinuation were examined in six subcategories: Failure (became pregnant while using), Method-related: (side effects, wanted a more effective method and inconvenient to us), Access (availability or cost), Unreliable reasons (Infrequent sex/husband away, Marital dissolution/separation, difficult to get pregnant/ menopausal): those are classified under unscheduled discontinuation because they are among the causes for failure and unwanted pregnancy and they are still didn't want to become pregnant, other reasons: (other, fatalistic, don't know) and husband opposed.

Cluster or community: means an enumeration area.

Reproductive age women: are women who are from 15 to 49 years old.

\section{Data collection, management and quality control}

The survey tool had 5 parts that are household questionnaire, woman's questionnaire, man's questionnaire, biomarker questionnaire and health facility questionnaire. The EDHS survey questionnaire assesses the household and respondent characteristics, fertility and family planning, maternal and child health, nutrition, HIV/AIDS, sexual violence, and others.

After the permission to download dataset of EDHS2016 has been received through electronic mail, selecting and extracting important variables related to contraceptive use discontinuation were performed from the data set.
Further data cleaning, labeling, coding and recoding were done for all selected variables. In addition categorization was done for continuous and categorical variables using information from different literatures or based on their clinical and public health importance.

\section{Analysis}

The data was taken from EDHS 2016, and analyzed using multilevel logistic regression in STATA version 14. In this study which assessed the effect of different predictors on the unscheduled contraceptive use discontinuation, only women of reproductive age ( 15 to 49 years old) who ever use contraceptive or discontinue a contraceptive use (recent one) for reasons other than desire to become pregnant, which is a public health interest, were included. Because the difference in discontinuation among different categories may be due to the difference of desire to become pregnant across those categories. Thus; women who discontinued for the reason of need to be pregnant as well as sterilized women, who didn't have history of discontinuation before sterilization, were excluded from the analysis. Why we prefer the recent discontinuation is for easily remembrance of the discontinued method and its reason (to reduce recall bias).

\section{Descriptive statistics}

Frequency and percentage were used to report categorical variables; mean for continuous normal variables, and median followed by Inter quartile Range, for continuous explanatory variables that violate assumption of normality, were also used. In addition cross tabulation was done to show the proportion of different categories of each characteristic with respect to the outcome variable (contraceptive use discontinuation).

\section{Multilevel logistic regression analysis}

Multilevel analysis can address the two main problems that can occur either due to aggregation or disaggregation of data. If data are aggregated we loss data and power, on the other hand if data are disaggregated and are not independent of one another, it can lead to false positive significant effect when in fact not exist [21].

Therefore; this study has an individual level dependent variable with dichotomous nature and individual and community level independent variables. Thus; we prefer multilevel logit regression analysis, for the last method discontinued, that simultaneously investigates community and individual level factors and reflects their effect on individual level outcome and therefore; the model produces appropriate estimates about the parameters (refer Table 1).

\section{Bivariate multilevel logistic analysis}

Bivariate regression analysis was performed to explore association between dependent variable and a wide range 
Table 1 Types of studies based on the nature of variables ( [21])

\begin{tabular}{lll}
\hline Independent Variable & Dependent Variable & Type of Study \\
\hline Group-Level & Group-Level & Ecological \\
Individual-Level & Individual-Level & Individual-Level \\
Group \& Individual Level & Individual-Level & Multilevel \\
\hline
\end{tabular}

of independent variables to identify the potential variable with $p$-value of 0.25 and less to be entered to the final model [22].

\section{Multivariable multilevel logistic analysis}

Variables with p-value of less than 0.05 in the final model were considered as significant predictors of contraceptive use discontinuation. Adjusted odds ratio (AOR) and 95\% confidence interval (CI) were used to report the findings of this study. Variance partition coefficient (VPC), proportional change in variance (PCV) and the median odds ratio which are measures of components of variance and heterogeneity in outcome were used to quantify the magnitude of the general contextual effect. To integrate the higher level fixed effect and the random residual variations, $80 \%$ interval odds ratio (IOR-80) which is summary measures of effect for cluster-level covariates was also used [23].

\section{Model fit statistics}

Receiver operating characteristics (ROC) curve was used to assess general accuracy of the model to the data set using the area under receiver operating characteristics (AUC). Relative goodness-of-fit test was conducted using akaike's information criteria (AIC) for each of the models and compared [24]. AIC is better in situations when a false negative finding would be considered more misleading than a false positive (for sensitive model), and BIC is better in situations where a false positive is as misleading as, or more misleading than, a false negative (for specific model) [25].

\section{Model diagnostics}

Multi-collinearity diagnostic evaluation was done using variance inflation factor (VIF), and thus value of VIF greater than 10, gives evidence of multi-collinearity [26]. The level-2 random residual was tested for its normal distribution.

\section{Model specification}

The focus of this study was on the random effects intercept, because I theorized only one individual level variable to vary its effect on the outcome across clusters (which is women education-but this random slope fitted was found to be insignificant, so not included in the final model, see Additional file 1).
Level 1: Model for individual level predictors (fixed effects):

$$
\log (\text { odds })=\beta_{0 j}+\beta_{1 j} x_{1 i j}+\beta_{2 j} x_{2 i j}+\ldots+\beta_{K j} x_{K i j}+e_{i j} .
$$

Level 2: Model for intercept and slopes (random effects):

Mixed model: $\log ($ odds $)=\beta_{00}+\left(B_{10}+u_{1 j}\right) * x_{i j}+\beta_{01} *$ $X_{j}+u_{0 j}+e_{i j}$.

$$
\begin{aligned}
\log (\text { odds })= & B_{00}+\left(\beta_{10}+u_{1 j}\right) * x_{i j}+\beta_{01} * X_{j} \\
& +\beta_{11} * x_{i j} * X_{j} \\
& +u_{0 j}(\text { if interaction is assumed }) .
\end{aligned}
$$

Where Log (odds) is the log-odds that the outcome variable equals one instead of zero (i.e. the chance that a pupil $i$ from a cluster $j$ discontinues contraceptive use), $\beta_{\mathbf{0 0}}$ is the fixed intercept, $u_{\mathbf{0}}$ is the deviation of the cluster-specific intercept from the fixed intercept (i.e. the level-2 residual), $\mathbf{x}_{\mathbf{i j}}$ refers to the level-1 variable, $\mathbf{X}_{\mathbf{j}}$ refers to the level-2 variable, $\beta_{10} \ldots \beta_{\text {ко }}$ are the fixed slopes of $\mathbf{x}_{\mathbf{i j}}$ (the level-1 variable), $u_{\mathbf{1} \mathbf{j}} \ldots \mathbf{u}_{\mathbf{K} \mathbf{j}}$ are the deviation of the cluster-specific slopes from the fixed slopes (i.e. the residual term associated with the level-1 variable) and $\beta_{01}$ is the fixed slope of $\mathbf{X}_{\mathbf{j}}$ (the overall effect of cluster level variable), $\beta_{11}$ is the coefficient estimate associated with the cross-level interaction [27].

\section{Result}

In this study, all the descriptive part tables and proportions are weighted unless indicated as un-weighted; because the EDHS data was coming from strata and clusters that are sampled disproportionately and for this reason the DHS manual recommends weighting to make the sample more representative.

\section{General description of the study participants}

In this study, a total of 3835 women who ever tried any contraceptive in the 5 years prior to the survey, excluding women having scheduled contraceptive discontinuation, were included in the analysis. The participants were nested in 529 communities. The numbers of women nested per community were ranged from 1 to 19 with a median of 7 and inter quartile range of 5 .

The mean age of the participants was 30.4 years $(\mathrm{SD}=$ $7.831)$, having a mean of 3.12 children $(\mathrm{SD}=1.798)$ per woman. More than half $(53.79 \%)$ of the participants were orthodox followers, more than one third $(42.99 \%)$ had no any work, $76.33 \%$ were from rural residents, $54.22 \%$ were uneducated and $28.08 \%$ were from the richest group of household wealth index. The prevalence of unscheduled contraceptive discontinuation was $46.18 \%$.

From the respondent's occupation, discontinuation rate was higher $(51.5 \%)$ among professional women. 
From the age category, older women were found to have highest contraceptive use discontinuation, whereas the younger women had lowest discontinuation rate. More than half $(52.1 \%)$ of women heading a household and $47.7 \%$ of women exposed to media had contraceptive use discontinuation (see Table 2).

Majority (58\%) of women: living in community with high contraceptive use rate, (61.4\%) residing in Tigray, and (57.1\%) residing in Adiss Ababa had high unscheduled contraceptive use discontinuation, whereas women living in low educated community and poor community had relatively low discontinuation rate of 45 and $44.7 \%$ respectively (see Table 3).

\section{Reasons of contraceptive discontinuation}

Most (71.37\%) of the discontinued methods were Injectables followed by long acting (13.21\%) and pills (10.95\%). Method related reasons were found to be the principal ones for unscheduled discontinuation of both short acting and long acting contraceptives. Of the reasons to discontinue a contraceptive utilization, $54.55 \%$ were method related (side effects, inconvenience, and needing better method). Contraceptive failure was reported highest in women of pill users (12\%) followed by injectable users (3.3\%) compared to the long acting methods. Only $6.45 \%$ women had a history of last method switched in to another method, while the unscheduled discontinuation is 46.18\% (refer Table 4).

\section{Multivariable multilevel logistic regression analysis Measures of components of variance and heterogeneity}

In the model building, the empty model (model-0), that had no predictor variable, showed that the proportion of variation on the unscheduled contraceptive discontinuation explained by the clustering effect was $11.12 \%$ using the logit-link and $13.5 \%$ using the probit-link; indicated that the presence of statistically significant variability on unscheduled contraceptive use discontinuation across the communities. The median odds ratio $(\mathrm{MOR}=1.844)$ reflected that the odds of unscheduled contraceptive use discontinuation was 1.844 times higher in the persons with the higher propensity to the outcome of interest compared to those persons with lower propensity.

The reported likelihood-ratio test showed that there was highly statistically significant variability $(p$-value $<0.001$ ) on unscheduled contraceptive discontinuation between women from different communities to favor a multilevel logistic regression over a standard logistic regression.

The estimated intercept of empty model was -0.088756 , and therefore; at an average community (whose specific intercept is equal to the fixed intercept), the probability of one episode unscheduled contraceptive use discontinuation within five years was 0.478 .
Table 2 Description and bivariate logistic analysis of individual level factors of unscheduled contraceptive discontinuation, EDHS 2016, January 2018

\begin{tabular}{lllll}
\hline \multirow{2}{*}{$\begin{array}{l}\text { Individual Level } \\
\text { Variables }\end{array}$} & \multicolumn{4}{l}{ Unscheduled Contraceptive Discontinuation } \\
\cline { 2 - 5 } Yes (\%) & No (\%) & Total (\%) & p-value \\
\hline Age category & & & & \\
$15-24$ & $404.1(42.8)$ & $539(57.2)$ & $943.1(24.6)$ & 0.001 \\
$25-34$ & $785.8(46.8)$ & $894.2(53.2)$ & $1680(43.8)$ & ----- \\
$35-49$ & $581.1(47.9)$ & $630.8(52.1)$ & $1211.9(31.6)$ & 0.609 \\
Number of children & & & & \\
$<=1$ & $494(42.6)$ & $665(57.4)$ & $1159(30.2)$ & $<0.001$ \\
$>=2$ & $1277(47.7)$ & $1399(52.3)$ & $2676(69.8)$ & ----- \\
Household head & & & & \\
Male & $1407.7(44.9)$ & $1729.6(55.1)$ & $3137.3(81.8)$ & ----- \\
Female & $363.4(52.1)$ & $334.3(47.9)$ & $697.7(18.2)$ & 0.001 \\
Respondent's occupation & & & \\
No occupation & $716.3(43.4)$ & $932.5(56.6)$ & $1648.8(43)$ & 0.002 \\
Professionals & $550.5(51.5)$ & $519(48.5)$ & $1069.5(28)$ & ----- \\
Services & $78.2(50.6)$ & $76.4(49.4)$ & $154.6(4)$ & 0.688 \\
Skilled manual & $366.1(44.2)$ & $462.6(55.8)$ & $828.7(21.6)$ & 0.085 \\
Unskilled manual & $27.1(51.4)$ & $25.7(48.6)$ & $52.7(1.3)$ & 0.439 \\
Others & $33(40.9)$ & $47.7(59.1)$ & $80.7(2.1)$ & 0.082
\end{tabular}

Respondent's education

$\begin{array}{lllll}\text { No education } & 950.1(45.7) & 1129(54.3) & 2079.1(54.2) & 0.537 \\ \text { Primary } & 545(46.6) & 623.3(53.4) & 1168.3(30.5) & ----- \\ \text { Secondary } & 148.3(45) & 181.1(55) & 329.4(8.6) & 0.762 \\ \text { Higher } & 127.6(49.4) & 130.5(50.6) & 258.2(6.7) & 0.708 \\ \text { Household wealth index } & & & \\ \text { Poorest } & 182.2(41.6) & 255.5(58.4) & 437.6(11.4) & 4.202 \\ \text { Poorer } & 320.6(45.8) & 379.1(54.2) & 699.7(18.2) & 2.210 \\ \text { Middle } & 376.4(47.1) & 423.1(52.9) & 799.5(20.9) & ----- \\ \text { Richer } & 370.8(45.2) & 450.4(54.8) & 821.2(21.4) & 1.147 \\ \text { Richest } & 521.1(48.4) & 555.9(51.6) & 1077(28.1) & 0.134 \\ \text { RELIGION } & & & & \\ \text { Orthodox } & 1040(50.4) & 1023(49.6) & 2063(53.7) & ----- \\ \text { Catholic } & 7.9(25.6) & 23(74.4) & 30.9(0.8) & 0.508 \\ \text { Protestant } & 283.9(31.8) & 609.2(68.2) & 893.1(23.3) & 0.000 \\ \text { Muslim } & 427.9(52) & 395.2(48) & 823.1(21.5) & 0.688 \\ \text { Traditional } & 6.2(57.9) & 4.5(42.1) & 10.7(0.3) & 0.704 \\ \text { Others } & 5(35.2) & 9.2(64.8) & 14.2(0.4) & 0.926\end{array}$

Heard about FP at community

Yes $\quad 851.9(49.6) \quad 865.9(50.4) \quad 1717.8(44.8) \quad$------

$\begin{array}{lllll}\text { No } & 919.2(43.4) & 1198(56.6) & 2117.2(55.2) & 0.011\end{array}$

Media exposure

Exposed $\quad 581.3(47.7) \quad 638.1(52.3) \quad 1219.4(31.8) \quad----$

$\begin{array}{lllll}\text { Not exposed } \quad 1189.7(45.5) & 1425.9(54.6) & 2615.6(68.2) & 0.057\end{array}$

(FP)-family planning, (------) reference category 
Table 3 Description and bivariate logistic analysis of community level factors of unscheduled contraceptive discontinuation, EDHS 2016 December 2018

\begin{tabular}{|c|c|c|c|c|}
\hline \multirow{2}{*}{$\begin{array}{l}\text { Community } \\
\text { Level Variables }\end{array}$} & \multicolumn{4}{|c|}{ Unscheduled Contraceptive Discontinuation } \\
\hline & Yes (\%) & No (\%) & Total (\%) & p-value \\
\hline \multicolumn{5}{|l|}{ Region } \\
\hline Tigray & $189.9(61.4)$ & $119.3(39.6)$ & $309.2(8.1)$ & 0.000 \\
\hline Afar & $3(29.4)$ & $7.2(70.6)$ & $10.2(0.3)$ & 0.002 \\
\hline Amhara & $627.6(50.7)$ & $609.3(49.3)$ & $1236.9(32.3)$ & 0.000 \\
\hline Oromia & $524.4(44.8)$ & $647.4(55.2)$ & $1171.8(30.6)$ & 0.076 \\
\hline Somali & $1.8(43.9)$ & $2.3(56.1)$ & $4.1(0.1)$ & 0.894 \\
\hline Benshangul & $15.8(44.4)$ & $19.8(55.6)$ & $35.6(0.9)$ & 0.120 \\
\hline SNNPR & $256.7(32.3)$ & $538.8(67.7)$ & $795.5(20.7)$ & 0.000 \\
\hline Gambella & $4.9(43.7)$ & $6.3(56.3)$ & $11.2(0.3)$ & 0.039 \\
\hline Harari & $3.1(43.7)$ & $3.95(56.3)$ & $7.1(0.2)$ & 0.160 \\
\hline Adiss abab & $134.2(57.1)$ & $100.7(42.9)$ & $234.9(6.1)$ & 0.081 \\
\hline Dire dawa & $9.5(51.9)$ & $8.8(48.1)$ & $18.3(0.5)$ & ------ \\
\hline \multicolumn{5}{|l|}{ Type of residence } \\
\hline Urban & $448.8(49.4)$ & $458.9(50.6)$ & $907.7(23.7)$ & \\
\hline Rural & $1322.2(34.5)$ & $1605.1(65.5)$ & $2927.3(76.3)$ & 0.003 \\
\hline \multicolumn{5}{|c|}{ Community contraceptive } \\
\hline Low & $467.2(58)$ & $337.8(42)$ & $805(30)$ & 0.000 \\
\hline High & $1303.8(43)$ & $1726.2(57)$ & 3030() & ----- \\
\hline \multicolumn{5}{|c|}{ Community education } \\
\hline Low & $1016.8(45)$ & $1242.4(55)$ & $2259.2(58.9)$ & 0.021 \\
\hline High & $754.3(47.9)$ & $821.5(52.3)$ & $1575.8(41.1)$ & ----- \\
\hline \multicolumn{5}{|c|}{ Community media } \\
\hline Not exposed & $903.8(44.1)$ & $1145.5(55.9)$ & $2049.3(53.4)$ & 0.000 \\
\hline Exposed & $867.2(48.6)$ & $918.5(51.4)$ & $1785.7(46.6)$ & ----- \\
\hline \multicolumn{5}{|c|}{ Community wealth } \\
\hline Poor & $838.5(44.7)$ & $1036.7(55.3)$ & $1875.3(48.9)$ & 0.000 \\
\hline Rich & $932.5(47.6)$ & $1027.2(52.4)$ & $1959.7(41.1)$ & ----- \\
\hline
\end{tabular}

FV health facility visit, $F W$ field worker, ------ reference category

NB: any descriptive table is weighted, unless indicated as un-weighted
In model-1, the MOR indicated that, $66.9 \%(\mathrm{MOR}=1.669)$ of increase in the odds of unscheduled contraceptive discontinuation among the women with higher propensity to the outcome was accounted by differences across communities. In addition the PCV in model-1 implied that less than onethird $(29.68 \%)$ of the variation due to differences across communities (general contextual effect) on unscheduled contraceptive discontinuation was explained by individual level predictors, and the ICC and MOR values decreased to $8.1 \%$ and 1.671 respectively from the null-model.

The MOR (1.457) in model-2 revealed that the clustering effect accounts for $45.7 \%$ increase on the odds of unscheduled contraceptive discontinuation and in the final model (MOR $=1.419) 41.9 \%$ increase in the odds of the outcome variable was attributed by differences across communities. The PCV on model-2 and model-3 revealed that 62.20 and $67.21 \%$ of the community variance in null-model was explained by adding community-level variables in model- 2 , and by adding both individual and community level variables in model-3 respectively (refer Table 5 ).

The LR-test stated that the multilevel logistic regression was significantly favored over a standard (ordinary) logistic regression for this clustered nature of data.

\section{ROC curve as measure of general contextual effect and goodness of fit}

When prediction is based on both fixed effects and posterior means of random effects, using predict probability, mu command in STATA, the AUC is used as a measure of general contextual effect and, the ICC and AUC are usually consistent (both, either high or low) [28]. In this study AUC, as a measure of general contextual effect, was found to be near consistent with ICC size which makes sense as expected.

Using predict probability, $\mathrm{xb}$ command in STATA, prediction is done based on only fixed effects. In this situation the AUC is a measure of goodness of fit which uses only fixed effect for prediction as AIC do. So, both are expected to give consistent decision. In this study, the final model was found to have relatively good fit, from both AIC and AUC values (refer Fig. 3).

Table 4 Frequency distribution of reasons of discontinuation for different contraceptive methods, from-EDHS 2016, January 2018

\begin{tabular}{|c|c|c|c|c|c|c|c|}
\hline \multirow{2}{*}{$\begin{array}{l}\text { Discontinued } \\
\text { methods }\end{array}$} & \multicolumn{7}{|c|}{ Reason to discontinue a contraceptive } \\
\hline & became pregnant (failure) & method related & Access & husband opposed & Unreliable reasons & other reasons & Total \\
\hline Pill & 23 & 106 & 13 & 1 & 39 & 12 & 194 \\
\hline Injectables & 41 & 710 & 116 & 27 & 241 & 129 & 1264 \\
\hline Long acting & 4 & 158 & 1 & 4 & 36 & 31 & 234 \\
\hline Male condom & 0 & 4 & 0 & 0 & 16 & 4 & 24 \\
\hline Other modern & 5 & 10 & 0 & 0 & 17 & 5 & 37 \\
\hline Traditional & 3 & 8 & 0 & 0 & 7 & 0 & 18 \\
\hline Total & 76 & 996 & 130 & 32 & 356 & 181 & 1771 \\
\hline
\end{tabular}

Other reasons $=($ fatalistic, don't know), method related reasons $=($ side effect, inconvenience, and needing better method) 
Table 5 measures of components of variance and heterogeneity on unscheduled contraceptive discontinuation, multilevel logistic regression analysis EDHS 2016, January 2018

\begin{tabular}{|c|c|c|c|c|}
\hline RANDOM EFFECTS & MODEL-0 & MODEL-1 & MODEL-2 & MODEL-3 \\
\hline \multicolumn{5}{|c|}{ Measure of general Contextual effect } \\
\hline ICC & $11.12 \%$ & $8.08 \%$ & $4.52 \%$ & $3.94 \%$ \\
\hline MOR & 1.844 & 1.671 & 1.457 & 1.419 \\
\hline Var & 0.4114 & 0.2893 & 0.1555 & 0.1349 \\
\hline PCV & & $29.68 \%$ & $62.20 \%$ & $67.21 \%$ \\
\hline AUC \% $(95 \% \mathrm{Cl})$ & $75.35(0.73835,0.76859)$ & $72.91(0.71338,0.74448)$ & $69.89(0.68255,0.71530)$ & $70.29(0.68659,0.71917)$ \\
\hline \multicolumn{5}{|l|}{ MODEL Selection } \\
\hline $\mathrm{AIC}$ & 5227.386 & 5189.581 & 5118.615 & 5106.208 \\
\hline AUC\% (Fixed effect only) & Reference & 59.94 & 63.13 & 64.83 \\
\hline Log-likelihood (LR-test p-value) & $-2611.6929(0.0000)$ & $-2567.79(0.0000)$ & $-2541.3073(0.0000)$ & $-2510.104(0.0002)$ \\
\hline
\end{tabular}

ICC intra-class correlation, MOR median odds ratio, Var random intercept variance, $P C V$ proportional change in variance, $A U C$ area under the curve, AIC akaki's information criteria, $\mathrm{Cl}$ confidence interval

\section{Multilevel factors associated with unscheduled discontinuation}

Household head, women's occupation, religion and number of children per woman were statistically significant predictors associated with unscheduled contraceptive discontinuation in Model-1. Residing in low educated community, rich community, and community with low contraceptive rate and regions were found to be significant predictors of unscheduled contraceptive discontinuation in Model-2. This is just to illustrate the variables that were significant in model- 1 and model-2, to see how those variables are modified to each other in the final best model (see Table 6).

\section{Final best model (Model-3): cross adjusted association}

In final model (model-3), both the individual level and community level variables were added at the same time; in which community-level factors modify the association

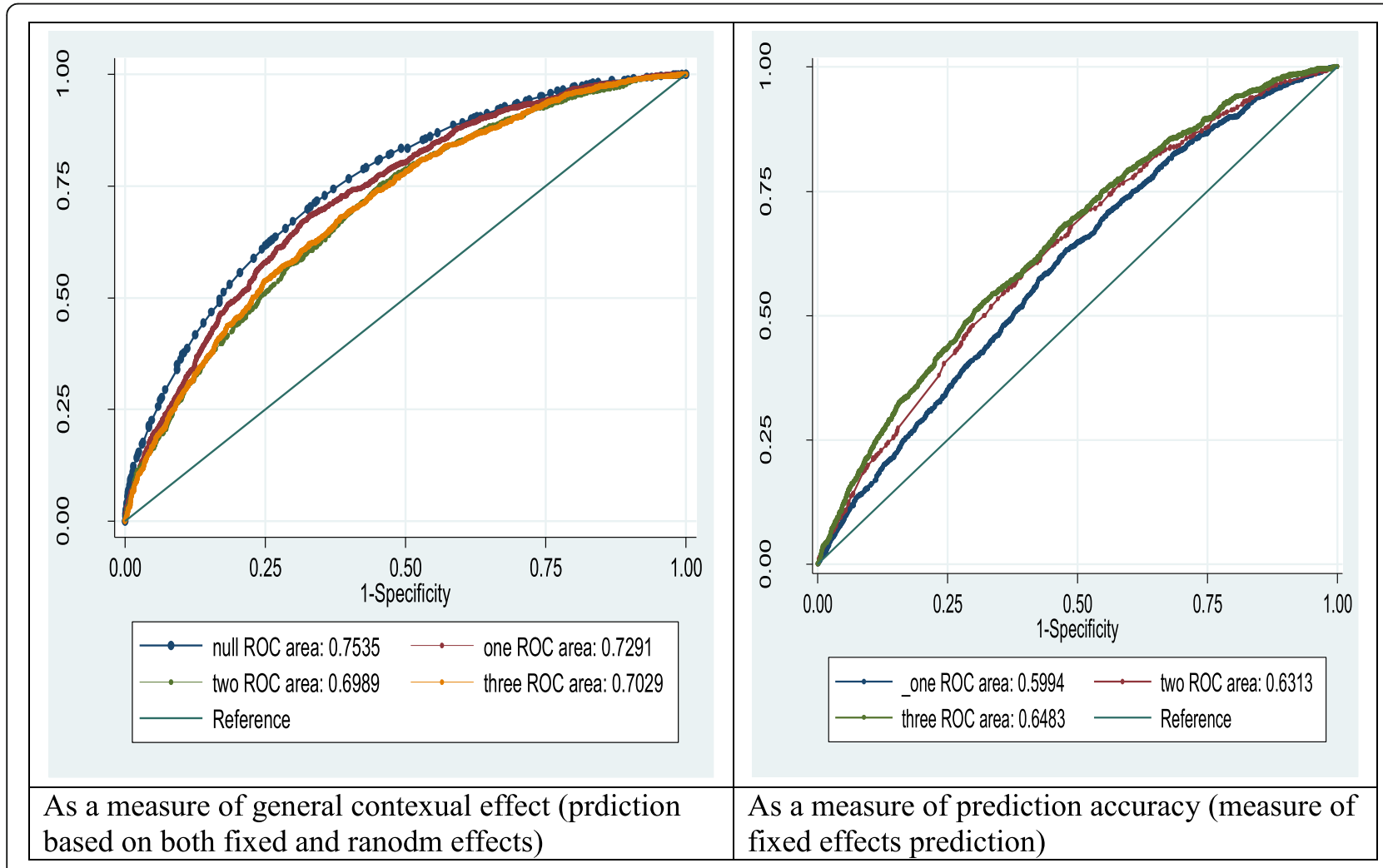

Fig. 3 ROC curves as a measure of general contextual effect and goodness of fit, EDHS 2016, January 2018 
Table 6 Multivariable multilevel logistic regression analysis of individual and community level factors associated with unscheduled contraceptive discontinuation, EDHS 2016, January 2018

\begin{tabular}{|c|c|c|c|}
\hline \multirow{2}{*}{$\begin{array}{l}\text { Fixed Effect Of } \\
\text { Variables }\end{array}$} & \multicolumn{3}{|l|}{ AOR $(95 \% \mathrm{Cl})$} \\
\hline & MODEL-1 & MODEL-2 & MODEL-3 \\
\hline \multicolumn{4}{|l|}{ Age group } \\
\hline $15-24$ & $0.885(0.72,1.088)$ & & $1.083(0.880,1.333)$ \\
\hline $25-34$ & 1 & & 1 \\
\hline $35-49$ & $0.891(0.737,1.077)$ & & $0.933(0.712,1.222)$ \\
\hline \multicolumn{4}{|l|}{ Media exposure } \\
\hline Not exposed & $0.939(0.792,1.116)$ & & $0.941(0.788,1.123)$ \\
\hline exposed & 1 & & 1 \\
\hline \multicolumn{4}{|c|}{ Heard about FP at Community event } \\
\hline Not heard & $0.881(0.762,1.018)$ & & $0.910(0.787,1.052)$ \\
\hline heard & 1 & & 1 \\
\hline \multicolumn{4}{|l|}{ Number of children } \\
\hline$<=1$ & $0.718(0.592,0.872)$ & & $0.682(0.561,0.828)^{*}$ \\
\hline$>=2$ & 1 & & 1 \\
\hline \multicolumn{4}{|l|}{ Household head } \\
\hline Male & 1 & & 1 \\
\hline Female & $1.316(1.109,1.561)$ & & $1.281(1.079,1.520)^{*}$ \\
\hline \multicolumn{4}{|c|}{ Respondent's occupation } \\
\hline No occupation & $0.793(0.658,0.955)$ & & $0.812(0.673,0.979)^{*}$ \\
\hline Professionals & 1 & & 1 \\
\hline Services & $1.016(0.727,1.419)$ & & $1.017(0.727,1.421)$ \\
\hline Skilled manual & $0.812(0.659,0.999)$ & & $0.834(0.676,1.029)$ \\
\hline Unskilled manual & $0.809(0.479,1.369)$ & & $0.739(0.439,1.241)$ \\
\hline Others & $0.653(0.424,1.006)$ & & $0.641(0.0 .416,0.987)$ \\
\hline \multicolumn{4}{|c|}{ Household wealth index } \\
\hline Poorest & $0.834(0.631,1.103)$ & & $0.753,(0.567,0.997)^{*}$ \\
\hline Poorer & $0.917(0.710,1.183)$ & & $1.206(0.912,1.594)$ \\
\hline Middle & 1 & & 1 \\
\hline Richer & $0.984(0.768,1.259)$ & & $1.269(0.946,1.702)$ \\
\hline Richest & $1.064(0.830,1.364)$ & & $1.089(0.758,1.566)$ \\
\hline \multicolumn{4}{|l|}{ RELIGION } \\
\hline Orthodox & 1 & & 1 \\
\hline Catholic & $0.723(0.299,1.747)$ & & $1.176(0.489,2.828)$ \\
\hline Protestant & $0.595(0.481,0.734)$ & & $0.822(0.646,1.046)$ \\
\hline Muslim & $0.985(0.813,1.193)$ & & $1.129(0.921,1.383)$ \\
\hline Traditional & $1.339(0.263,6.832)$ & & $1.324(0.260,6.745)$ \\
\hline Others & $1.053(0.303,3.654)$ & & $1.207(0.343,4.242)$ \\
\hline \multicolumn{4}{|l|}{ Region } \\
\hline Tigray & & $1.847(1.264,2.701)$ & $1.883(1.267,2.798)^{*}$ \\
\hline Afar & & $0.379(0.202,0.713)$ & $0.370(0.196,0.697)^{*}$ \\
\hline Amhara & & $1.394(0.956,2.031)$ & $1.333(0.906,1.963)$ \\
\hline Oromia & & $0.901(0.610,1.329)$ & $0.903(0.611,1.963)$ \\
\hline Somali & & $0.718(0.270,1.911)$ & $0.655(0.245,1.754)$ \\
\hline
\end{tabular}


Table 6 Multivariable multilevel logistic regression analysis of individual and community level factors associated with unscheduled contraceptive discontinuation, EDHS 2016, January 2018 (Continued)

\begin{tabular}{|c|c|c|c|}
\hline \multirow{2}{*}{$\begin{array}{l}\text { Fixed Effect Of } \\
\text { Variables }\end{array}$} & \multicolumn{3}{|c|}{ AOR (95\% Cl) } \\
\hline & MODEL-1 & MODEL-2 & MODEL-3 \\
\hline Benshangul & & $0.991(0.653,1.505)$ & $0.924(0.605,1.412)$ \\
\hline SNNPR & & $0.691(0.419,0.914)$ & $0.682(0.451,1.031)$ \\
\hline Gambella & & $0.887(0.581,1.355)$ & $1.004(0.653,1.544)$ \\
\hline Harari & & $0.804(0.523,1.234)$ & $0.768(0.499,1.182)$ \\
\hline Adiss abab & & $1.398(0.979,1.997)$ & $1.474(1.030,2.108)^{*}$ \\
\hline Dire dawa & & 1 & 1 \\
\hline \multicolumn{4}{|c|}{ Community contraceptive } \\
\hline Low & & $1.984(1.651,2.383)$ & $1.945(1.618,2.339)^{*}$ \\
\hline High & & 1 & 1 \\
\hline \multicolumn{4}{|c|}{ Community education } \\
\hline Low & & $1.313(1.052,1.639)$ & $1.246(0.998,1.556)$ \\
\hline High & & 1 & 1 \\
\hline \multicolumn{4}{|c|}{ Community wealth } \\
\hline Poor & & $0.748(0.595,0.942)$ & $0.763(0.596,0.977)^{*}$ \\
\hline Rich & & 1 & 1 \\
\hline \multicolumn{4}{|c|}{ Community media } \\
\hline Not exposed & & $0.919(0.735,1.151)$ & $0.957(0.763,1.201)$ \\
\hline exposed & & 1 & 1 \\
\hline \multicolumn{4}{|l|}{ Residence } \\
\hline Rural & & $0.835(0.636,1.095)$ & $0.768(0.557,1.06)$ \\
\hline Urban & & 1 & 1 \\
\hline
\end{tabular}

(1)-reference category, $\left(^{*}\right)$ - indicates significant predictors

between individual level factors and unscheduled contraceptive use discontinuation.

After adjusting the individual and community level characteristics and after fixing the random effects, women who were a head of household were 1.28 (AOR = 1.275 , 95\%CI 1.075-1.513) more likely to experience unscheduled contraceptive discontinuation compared to women of male headed households.

Keeping other variables constant, women who had no work were $19.4 \%$ (AOR $=0.806,95 \%$ CI $0.669,0.973$ ) lower to have unscheduled contraceptive discontinuation when compared to professional women (government and NGOs employee). The odds of unscheduled contraceptive use discontinuation was $24.7 \%$ ( $\mathrm{AOR}=0.753,95 \% \mathrm{CI} 0.567,0.997$ ) lower on women living in poorest house hold income quintile compared to middle house hold income quintile.

After holding the other individual and community level variable constant, residing in Tigray region was 1.939 times $(\mathrm{AOR}=1.939,95 \% \mathrm{CI} 1.306,2.879)$ higher, residing in Afar region was $62.5 \%(\mathrm{AOR}=0.375,95 \% \mathrm{CI}$ $0.199,0.707)$ lower and residing in Adiss-Ababa administrative city was 1.507 times $(\mathrm{AOR}=1.507,95 \% \mathrm{CI}$ $1.054,2.154$ ) higher to discontinue contraceptive use despite the desire to avoid pregnancy compared to Diredawa residents. Comparing women residing in community with low contraceptive utilization rate to women living in community with high contraceptive utilization rate, the odds of unscheduled contraceptive discontinuation was about 2 times higher $(\mathrm{AOR}=1.922,95 \% \mathrm{CI}$ $1.599,2.309)$ among the former ones. Adjusting for other variables, the odds of unscheduled contraceptive discontinuation was 22.6\% (AOR $=0.774$, 95\%CI $0.605-$ $0.990)$ less likely for women residing in poor community compared to women residing in rich community. Controlling for other variables, women who had $<=1$ child were $31.8 \%$ (AOR 0.682, 95\%CI 0.561, 0.828) lower to have unscheduled contraceptive use discontinuation compared to women who had two and above children (refer Table 6).

Those multilevel factors were tested for multicollinearity and no variable was found to have problematic multi-collinearity with VIF value $>10$.

\section{Summary measures of effect for cluster-level covariates}

The interval odds ratios (IOR) of the three significant community level predictors (community wealth, community 
contraceptive use rate and region) were 0.3925-1.486, $0.999-3.786$, and $0.968-3.664$ respectively. Here the IOR provided complementary information to the information provided by usual AOR in comparison to the residual community level variation, those significant variables were not important to understand community level variation in the individual propensity for experiencing unscheduled contraceptive discontinuation i.e. the effect of the those higher-level variables is not strong given the residual betweencommunity variation.

This analysis of IOR indicates that there are strong community-level effects on contraceptive use discontinuation which were not accounted for by the community-level variables included in the model. Further investigation of these community-level effects is an important area of research.

\section{Discussion}

This study delivers important insights in to the unscheduled contraceptive discontinuation from Ethiopian demographic and health survey of 2016 data. The objective of this study was assessment of reasons and multilevel factors associated with unscheduled contraceptive use discontinuation. The discussion would be focusing on methods discontinued, reasons of discontinuation, individual level factors and community level factors.

NB: The discussion about multilevel factors is all about the findings from the final model (the best model selected using both AUC and AIC).

\section{Methods discontinued}

IUD and implant discontinuation rates were lowest compared to others. This is like finding of the study conducted in Maryland, low income countries, urban Senegal and 60 DHS of countries $[1,4,29,30]$. This lowest discontinuation of long acting reversible contraceptive could be due to low side effects and greater efficacy compared to the hormonal contraceptives, and the need of health care provider for removal might give another chance to get further counseling from health care professionals.

\section{Reasons for discontinuation}

In this study, among women who have unscheduled discontinuation, more than half of discontinuations were for the reason of failure or method-related problems which is similar to the study done in low income countries [29], and the principal reason for unscheduled contraceptive discontinuation was method related reasons and this is in agreement with the studies done in London, India-2016, Senegal, Cambodia, and Pakistan [1, 30-33]. This might be because of increasing women's interests to concern more about their health and therefore; go to search for other better methods, being stressed with minor side effects and needing more convenient contraceptive method.

This study implied that discontinuation due to access was few which is similar to the studies done in 60 DHS of countries, Cambodia, Bangladesh, Guatemala, and Calverton [4, 32, 34-36]. Family planning is coordinated by different NGOs and governmental organizations freely, and this could improve the access. Other reasons are found to be the main reasons of condom use discontinuation compared to method related reasons which is similar to the study done in India [33].

\section{Significant individual level factors}

In this study, women of reproductive age who had more children were found to be more likely to have unscheduled contraceptive discontinuation. This is in agreement with study done in India and in Bangladesh [33, 36], and this could be similar to the critical review study done in 2015 that revealed women aged 25-34 years old were more likely to have discontinued than women aged less than 20 years [37] who could have lower number of children. This is may be due to the reason of thinking as reaching menopausal period by the older mothers. A study done in Bangladesh stated that contraceptive failure and abandonment while in need are more likely among middle age women compared to the younger counter parts and among women with more children [38]. In addition the older mothers may come across different contraceptive method that may be faced different method related problems, and this in turn may make them to be non-tolerant to minor inconveniences in the later methods.

This study implied that the odds of unscheduled contraceptive discontinuation were higher in professionals than those who had no occupation; this could be parallel to the study done in Bangladesh and critical review study of 2015 which implied that discontinuation was higher among educated women compared to women with no formal or with less education [36, 37]. Myths and rumors are often created and reinforced by women's social interactions at places where they gather and exchange information [39]. So those professional women may have higher social interactions to get myths and misconceptions to discontinue their utilization. In addition, Different researches showed that the highest knowledge, but low contraceptives practice; making the situation a serious challenge in which knowledge on contraceptives did not match with high contraceptive practice [40-42]. This indicates that not access and awareness only are enough to increase contraceptive practice, but improving counseling about contraceptive side effects; generally about method related problems and switching are necessarily important. Thus, the reason to professional women to have higher discontinuation might be poor switching encouragement, and poor counseling to address method related 
problems. More over; the professionals may also easily be dissatisfied by the family planning services to discontinue their contraceptive use, as their expectation may be beyond the actual quality when compared to the non-professional.

The odds of unscheduled contraceptive discontinuation was higher in these living in middle income quintile than living in poorest income quintile in line to the study done in Bangladesh and Pakistan [31, 38]. Most of reproductive age women, who have more interpersonal interaction, know incorrect information about family planning methods; and these women who have heard false and misleading information would have a negative attitude about family planning practicing at the time they heard $[43,44]$. Thus the women with middle income may have greater chance of interpersonal interactions to hear this false and misleading information, than the poorest women, to discontinue their contraceptive use.

This study also stated that women heading a household were found to have higher odds of unscheduled discontinuation compared to their counter parts (women who are not heading a household). This heading of household may increase the participation of women in social issues and may increase their chance to get contraceptive related information that could be accurate, misconceptions or rumors; and may also increase their concern to their health. Hence, those women may be sensitive to minor method inconveniences which may make them to have high discontinuation compared to women having a life of individualism. In addition, the women who are heading a house hold may be those who are divorced, not married and whose husbands are away or died. Such women are prone to unreliable reasons of discontinuation (like infrequent sex/husband away, marital dissolution/separation).

\section{Significant community level factors}

This study showed, women residing in community with higher contraceptive use rate had lower odds of unscheduled contraceptive use discontinuation compared to women living in community with lower contraceptive use rate which is similar to studies done in CalvertonMaryland, sixty DHS countries and low income countries $[4,29,35]$. This might be because of women living in communities with greater contraceptive rate may receive more peer support to continue contraceptive use if they have problems, and may receive more peer pressure not to have unwanted pregnancies. In addition, these communities may positively relax their norms and cultures towards continuous utilization of contraceptive use, as users increase.

Region, similar to several studies $(33,38,41$, and 46$)$, was found to be significant predictors of unscheduled contraceptive use discontinuation. This is may be due to different commitments towards reducing discontinuation among the different regions; and in addition to that, it could be due to the difference in knowledge and socioeconomic characteristics among the different regions.

Community wealth, similar to studies [34, 42], was found to be significant predictors of unscheduled contraceptive use discontinuation from the AOR. The wealthier communities may have higher knowledge on family planning, but different researches showed that the highest knowledge on contraceptives did not match with high contraceptive practice [40-42]. In addition, the wealthier communities may have more social interactions in which myths and rumors, which lead to discontinuation, could be exchanged.

\section{Strength and limitation \\ Strength}

- DHS data has individual (women) level sampling weight that is used to weight the descriptive part to make it more representative.

\section{Limitation}

- DHS data has no cluster level weighting which is, in multilevel modeling, necessary for performing weighted analysis (for the analytical part).

- Some variables included in the model might not be collected at the same date of the event occurrence

\section{Conclusion}

The prevalence of unscheduled contraceptive use discontinuation was $46.18 \%$. Of the last contraceptive methods discontinued while in need, majority were Injectables followed by long acting and pills. The principal reason of contraceptive use discontinuation was method related problems. Unscheduled contraceptive use discontinuation was higher among women residing in Tigray and Addis Ababa (compared to Dire-dawa), higher among women living in community with low contraceptive use rate (compared to high), higher among women having many children (compared to having 1-child), lower among women with poorest income quintile (compared to middle), lower among women not heading household (compared to women heading household), and lower among women with no occupation (compared to professionals). IOR-80\% implied the presence of other important community level variables, not considered in the model, that need to be considered. The outcome was common in groups who could have more social interactions and knowledge on which myths and rumors are common. So strengthening the efforts to reduce contraceptive use discontinuation and quality of contraceptive service provision could be important. 


\section{Supplementary information}

Supplementary information accompanies this paper at https://doi.org/10. 1186/s12889-019-8088-z.

Additional file 1. STATA output for random slope of the variable women's education

\section{Abbreviations}

AIC: Akaiki's Information Criteria; AUC: Area under the Receiver Operating Characteristic; BIC: Bayesian Information Criteria; CPR: Contraceptive Prevalence Rate; CSA: Central Statistical Agency; DHS: Demographic Health Survey; EDHS: Ethiopian Demographic Health Survey; ICC: Intra-Cluster Correlation Coefficient; IOR: Interval Odds Ratio; IRB: Institutional Review Board; IUDs: Intrauterine Devices; LARC: Long Acting Reversible Contraceptives; MLRM: Multilevel Logistic Regression Model; MOR: Median Odds Ratio; PCV: Proportional Change in Variance; ROC: Receiver Operating Characteristic; SDG: Sustainable Development Goal,; VIF: Variance Inflation Factor; VPC: Variance Partition Coefficient; WHO: World Health Organization

\section{Acknowledgments}

We are thankful to Mekelle University, Aksum University and central statistical agency, Ethiopia for allowing and supporting us to conduct this study.

\section{Authors' contributions}

The principal investigator, KT, had a major contribution in designing and planning of the research; and in extraction and analysis of the data as well. KE and HT have greatly assisted in analyzing the data as well as in preparing the manuscript. All authors read and approved the final manuscript.

\section{Funding}

This research has been partially funded by Mekelle University. The funding institution was receiving progress report of the research and giving comments accordingly.

\section{Availability of data and materials}

The data set used in this study had not been released to public. According to relevant regulations, the data cannot be shared publicly. However, the extracted data can be obtained from the corresponding author up on reasonable request. The source data can also be obtained from major DHS through Email if there is satisfactory reason to access the data. But this data is not publicly available.

\section{Ethics approval and consent to participate}

Ethics approval was obtained from the research ethics review committee of Mekelle University, College of Health Sciences and the consent to participate was guaranteed by the ethics review committee and DHS program since an already existing data were used. However, confidentiality, and privacy of the data were considered.

\section{Consent for publication}

Not applicable.

\section{Competing interests}

No competing interests.

\section{Author details}

${ }^{1}$ Department of Biostatistics, School of Public Health, College of Health Sciences, Aksum University, P.O.Box: 298, Axum, Ethiopia. ${ }^{2}$ Department of Biostatistics, School of Public Health, College of Health Sciences, Mekelle University, Mekelle, Ethiopia.

Received: 4 June 2019 Accepted: 15 December 2019 Published online: 27 December 2019

\section{References}

1. Sarah Castle, Ian Askew. Contraceptive discontinuation: reasons, challenges, and solutions. London: Population Council:FP-2020, December 2015.

2. Starbird E, Norton M, Marcus R. Investing in Family Planning: Key to Achieving the Sustainable Development Goals. Glob Health Sci Pract. 2016; 4(2):191-210.
3. Jain A, Obare F, RamaRao S, Askew I. Reducing unmet need by supporting women with met need. Int Perspect Sex Reprod Health. 2013;39(3):133-41.

4. Ali MM, Cleland J, Shah $\mathrm{H}$. Causes and consequences of contraceptive discontinuation. Evidence from 60 demographic and health surveys. 20 Avenue Appia1211,Geneva 27, Switzerland:: WHO; 2012.

5. Blumenthal PD, Voedisch A, Gemzell-Danielsson K. Strategies to prevent unintended pregnancy: increasing use of long-acting reversible contraception. Hum Reprod Update. 2011;17(1):121-37.

6. Ali MM, Cleland J. Contraceptive switching after method-related discontinuation: levels and differentials. Stud Fam Plan. 2010;41:129-33.

7. Bradley SEK, Croft TN, Rutstein SO. The impact of contraceptive failure on unintended births and induced abortions: estimates and strategies for reduction. ICF Macro: DHS Analytical Studies. Calverton; 2011.

8. Jain AK, Winfrey W. Contribution of Contraceptive Discontinuation to Unintended Births in 36 Developing Countries. Stud Fam Plann. 2017;48(3): 269-78

9. Barden-O'Fallon J, Speizer I. What differentiates method stoppers from switchers? Contraceptive discontinuation and switching among Honduran women. Int Perspect Sex Reprod Health. 2011;37(1):16-23.

10. Anrudh K., Jain (PhD). The Leaking Bucket Phenomenon in Family Planning. FP2020, September 2014.

11. Curtis S, Evens E, Sambisa W. Contraceptive discontinuation and unintended pregnancy: an imperfect relationship. Int Perspect Sex Reprod Health. June 2011;37(2):58-66.

12. Blanc AK, Curtis SL, Croft TN. Monitoring contraceptive continuation: links to fertility outcomes and quality of care. Stud Fam Plan. 2002;33:127-40.

13. Tsui AO, Brown W, Li Q. Contraceptive practice in sub-Saharan Africa. Popul Dev Rev. 2017;43(1):166-91.

14. Bekele T, Gebremariam A, Tura P. Factors associated with contraceptive discontinuation in Agarfa District, bale zone. South East Ethiopia. 2015;5:179.

15. Yideta ZS, Mekonen L, Seifu W, Shine S. Contraceptive discontinuation, method switching and associated factors among reproductive age women in Jimma town. Southwest Ethiopia Fam Med Med Sci Res February. 2017;6:213.

16. Pegu B, Gaur BPS, Sharma N, Singh AS. Knowledge, attitude and practices of contraception among married women. Int J Reprod Contracept Obstet Gynaecol. 2014;3(2):385-8.

17. Merlo J, Chaix B, Ohlsson H, Beckman A, Johnell K, Hjerpe P, et al. A brief conceptual tutorial of multilevel analysis in social epidemiology: using measures of clustering in multilevel logistic regression to investigate contextual phenomena. J Epidemiol Community Health. Apr 2006;60(4):290-7.

18. Callahan RL. Becker S. The Reliability of Calendar Data for Reporting Contraceptive Use: Evidence from Rural Bangladesh Stud Fam Plann. 2012; 43(3):213-22.

19. EMOH. FP2020. Actions for acceleration. Ethiopian minstry of health: Ethiopia; 2018-2019.

20. Central Statistical Agency - CSA/Ethiopia, ICF. Ethiopia Demographic and Health Sruvey 2016. Addis Ababa: CSA and ICF. p. 2017.

21. Diez-Roux AV. Bringing context back into epidemiology: variables and fallacies in multilevel analysis. Am J Public Health. 1998;88(2):216-22.

22. Stoltzfus JC. Logistic regression: a brief primer. Acadamic Emergency Medicine. 2011;18:1099-104.

23. Merlo J, Chaix B, Ohlsson H, Beckman A, Johnell K, Hjerpe P, et al. A brief conceptual tutorial of multilevel analysis in social epidemiology: using measures of clustering in multilevel logistic regression to investigate contextual phenomena. J Epidemiol Community Health. Apr 2006;60(4):290-7.

24. Okigbo C, Speizer I, Domino M, Curtis S. A multilevel Logit estimation of factors associated with modern contraception in urban Nigeria. World medical and health policy. March. 2017;9(1):65-88.

25. Dziak JJ, Coffman DL, Lanza ST, Runze L. Sensitivity and specificity of information criteria. Pennsylvania: The Pennsylvania State University June 27, 2012 Contract No.: 12-119.

26. Vatcheva KP, Lee M, McCormick JB, Rahbar MH. Multicollinearity in Regression Analyses Conducted in Epidemiologic Studies. Epidemiology (Sunnyvale). 2016 April;6(2)

27. Sommet N, Morselli D. Keep calm and learn multilevel logistic modeling: a simplified three-step procedure using Stata, R, Mplus, and SPSS. International Review of Social Psychology. Sep 2017:30(1):203-18.

28. Van Oirbeek R, Lesaffre E. Assessing the predictive ability of a multilevel binary regression model. Computational Statistics and Data Analysis. 2012; 56(6):1966-80 
29. Staveteig S, Mallick L, Winter R. Uptake and Discontinuation of LongActing Reversible Contraceptives (LARCS) in Low-Income Countries. DHS Analytical Studies Rockville, Maryland, USA:ICF International. 2015:No. 54.

30. Barden-O'Fallon J, Speizer IS, Calhoun LM, Corroon M. Women's contraceptive discontinuation and switching behavior in urban Senegal, 2010-2015. BMC Womens Health. 2018;18:35.

31. Khanewal, Khan RY, Khairpur, Umerkot, Mardan, Mansehra, et al. Low Use and High Discontinuation of Modern Contraceptives in Pakistan: Reasons and Policy Recommendations. Pakistan Population council, 2014.

32. Wang, Wenjuan, and Rathavuth Hong. Contraceptive Discontinuation, Failure, and Switching in Cambodia. Further Analysis of the 2014 Cambodia Demographic and Health Survey. DHS Further Analysis Reports No. 105. Rockville, Maryland, USA:ICF. 2015

33. Agrahari K, Mohanty SK, Chauhan RK. Socio-economic differentials in contraceptive discontinuation in India. SAGE. April-June 2016;6(2):1-16.

34. Barden-O'Fallon J. Peizer I, white J. association between contraceptive discontinuation and pregnancy intentions in Guatemala. Rev Panam Salud Publica. 2008;23(6):410-7.

35. Bradley, Sarah E. K, Hilary M. Schwandt, Shane Khan. Levels, Trends, and Reasons for Contraceptive Discontinuation:DHS Analytical Studies. Calverton, Maryland, USA: ICF Macro. 2009:No. 20.

36. Mahumud RA, Hossain MG, Sarkar AR, Islam MN, Hossain MR, Saw A, et al. Prevalence and associated factors of contraceptive discontinuation and switching among Bangladeshi married women of reproductive age. Open Access J Contracept. 2015;2015(6):13-9.

37. Inoue K, Barratt A, Richters J. Does research into contraceptive method discontinuation address women's own reasons? A critical review. BMJ Sexual Reproductive Health. 2015;41(2015):243-4.

38. Shahanara HS, Rahman MM. Factors associated with contraceptive failure, discontinuation and switching among married women in Bangladesh. Journal of familly welfare. December. 2007;53(2):43-55.

39. Gueye A, Speizer IS, Corroon M, Okigbo CC. Belief in family planning myths at the individual and community levels and modern contraceptive use in urban Africa. Int Perspect Sex Reprod Health. 2015 Dec;41(4):191-9.

40. Tilahun T, Coene G, Luchters S, Kassahun W, Leye E, Degomme O. Family planning knowledge, attitude and practice among married couples in Jimma zone. Ethiopia PLOS ONE. 2013:8(4):61-335.

41. Menhaden AL, Khalil AO, Hamdan-Mansour AM, Sato T, Imoto A. Knowledge, attitudes, and practices towards family planning among women in the rural southern region of Jordan. East Mediterr Heal J. 2012; 18(6):1-6.

42. Handady SO, Naseralla K, Sakin HH, Alawad AAM. Knowledge, attitude, and practice of family planning among married women attending primary health centerin Sudan. Int J Public Heal Res. 2015:3(5):243-7.

43. Goel MK, Goel M. Contraceptive practices and related factors among female in predominantly rural Muslim area of North India. Internet J World Heal Soc Polit. 2008;5(1):1-5.

44. Oyedokun AO. 1:1-14. Determinants of contraceptive usage: lessons from women in Osun state, Nigeria. J Humanit. Soc Sci. 2007;1:1-14.

\section{Publisher's Note}

Springer Nature remains neutral with regard to jurisdictional claims in published maps and institutional affiliations.

Ready to submit your research? Choose BMC and benefit from:

- fast, convenient online submission

- thorough peer review by experienced researchers in your field

- rapid publication on acceptance

- support for research data, including large and complex data types

- gold Open Access which fosters wider collaboration and increased citations

- maximum visibility for your research: over $100 \mathrm{M}$ website views per year

At $\mathrm{BMC}$, research is always in progress.

Learn more biomedcentral.com/submissions 